University of Nebraska - Lincoln

DigitalCommons@University of Nebraska - Lincoln

Spring 1999

\title{
In situ STEM Technique for Characterization of Nanoscale Interconnects During Electromigration Testing
}

Ismail Gobulukoglu

University of Nebraska-Lincoln

Brian W. Robertson

University of Nebraska-Lincoln, brobertson1@unl.edu

Follow this and additional works at: https://digitalcommons.unl.edu/mechengfacpub

Part of the Mechanical Engineering Commons

Gobulukoglu, Ismail and Robertson, Brian W., "In situ STEM Technique for Characterization of Nanoscale Interconnects During Electromigration Testing" (1999). Mechanical \& Materials Engineering Faculty Publications. 11.

https://digitalcommons.unl.edu/mechengfacpub/11

This Article is brought to you for free and open access by the Mechanical \& Materials Engineering, Department of at DigitalCommons@University of Nebraska - Lincoln. It has been accepted for inclusion in Mechanical \& Materials Engineering Faculty Publications by an authorized administrator of DigitalCommons@University of Nebraska Lincoln. 


\title{
IN SITU STEM TECHINIQUE FOR CHARACTERIZATION OF NANOSCALE INTERCONNECTS DURING ELECTROMIGRATION TESTING
}

\author{
Ismail Gobulukoglu and Brian W. Robertson \\ Department of Mechanical Engineering and the Center for Materials Research and Analysis \\ University of Nebraska, Lincoln, Nebraska 68588-0656
}

\section{Abstract}

A technique for observing microstructure and morphology changes during annealing or electromigration of $100 \mathrm{~nm}$-scale and smaller interconnects is presented. The technique is based on dynamic in situ characterization using a UHV field-emission scanning transmission electron microscope (STEM) and can enable full microstructural characterization (images, diffraction patterns and compositions) during electromigration testing. Initial steps in the validation of the approach include in situ electron-beam OMCVD of Al-containing wires and observation of these wires. Although the deposition conditions were not optimized, Al-containing wires, with high edge acuity, thickness uniformity, and with minimum interconnect widths as small as $15 \mathrm{~nm}$ have successfully been deposited. In situ imaging of the annealing of $100 \mathrm{~nm} \mathrm{Al} \mathrm{films} \mathrm{on} 25 \mathrm{~nm} \mathrm{Si} 3 \mathrm{~N}_{4}$ substrates at $350^{\circ} \mathrm{C}$ demonstrates that an image resolution of $10 \mathrm{~nm}$ should readily be attainable in passivated nanoscale interconnects during electromigration.

\section{Introduction}

Direct observation has given dynamic information on electromigration damage in micronscale or wider interconnects for the past 30 years. A number of tools have been employed for in situ electromigration observation of interconnects. These include scanning electron microscopy (SEM) $[1,2,3]$, transmission electron microscopy (TEM) [4,5,6,7], atomic force microscopy (AFM) [8], focussed ion beam (FIB) [9], $\mu$-reflection high energy electron diffraction microscopy $(\mu$-RHEED) [10], and microbeam x-ray diffraction (MXRD) [11].

More complete dynamic real time characterization of interconnects is key to understanding the fundamental mechanisms present during electromigration. However, this generally becomes more difficult to achieve as the interconnect widths scale down much below 1 micron. A side view transmission method of sufficient resolution and yielding sufficient signal. is required. Here, we propose a side view approach that will enable researchers to obtain quite complete information on changes in microstructure of interconnects during electromigration.

At the deep submicron scale, there are few tools that can provide characterization of one or more aspects of the surface and internal structure of interconnects encapsulated in dielectric. The choice of tool must enable strain and other information to be acquired from very small regions - $10 \mathrm{~nm}$ or less in the case of 100 to $200 \mathrm{~nm}$ wide interconnects. This limits the choice to field emission STEM, field emission (S)TEM, or, perhaps in future, a form of $x$-ray nanodiffraction / imaging. Of these, field emission STEM methods are the most applicable. We therefore propose UHV field emission STEM as a primary tool for in situ investigation during electromigration testing. The UHV fieid emission STEM is designed for optimum use of a small probe to analyze different regions within a sample and to permit acquisition of many signals simultaneously. One can obtain real time dynamic information, including efficient mass thickness 
mapping (annular dark field images), elemental mass and spectra, surface topography, crystal structure including misorientations at grain boundaries, compositional information, stress build up from strain measurements as well as electrical characterization from the interconnects during the electromigration testing, as illustrated schematically in Figure 1.

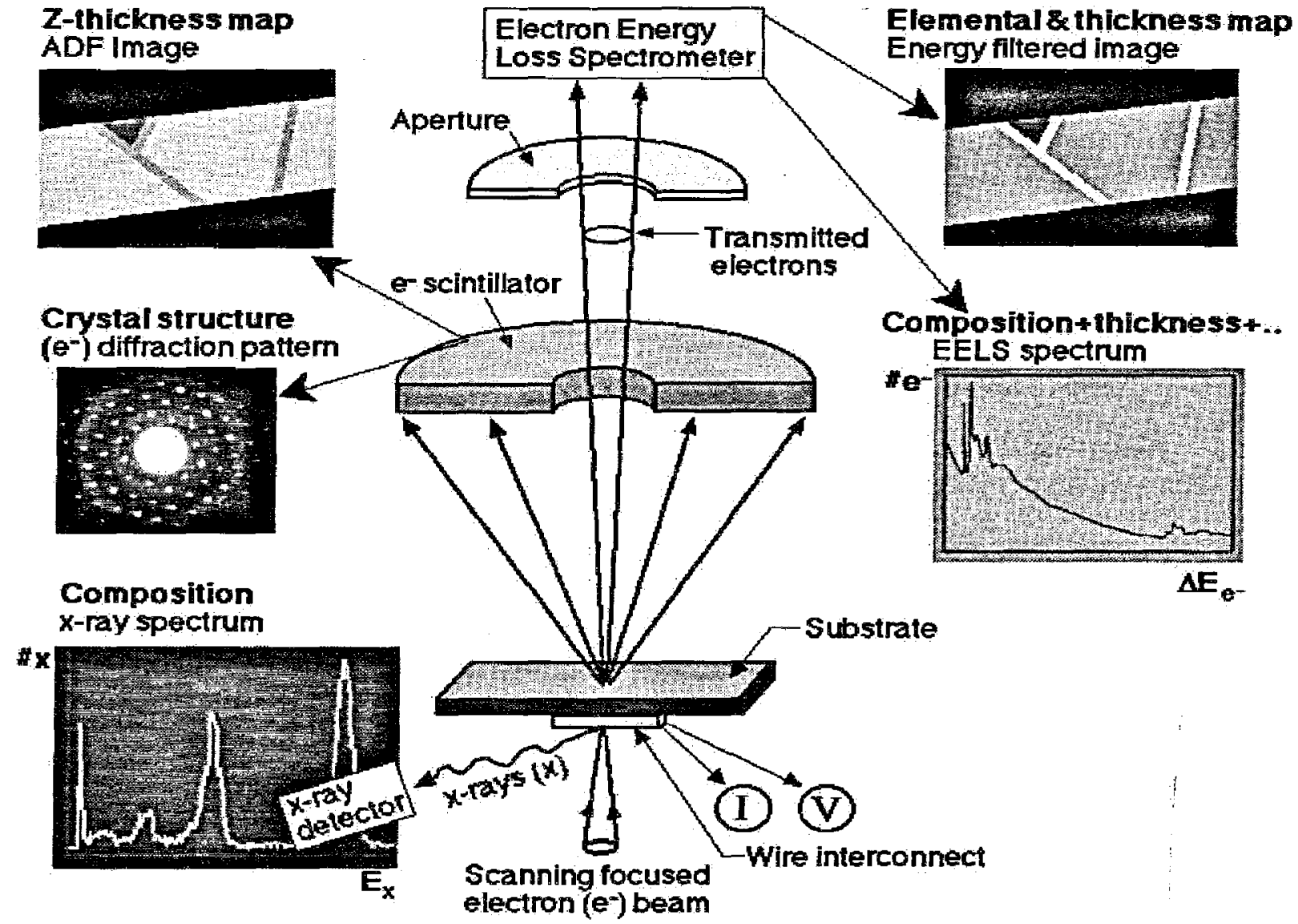

Figure 1. Schematic arrangement of in situ STEM that can provide simultaneous structural and other information during electromigration testing.

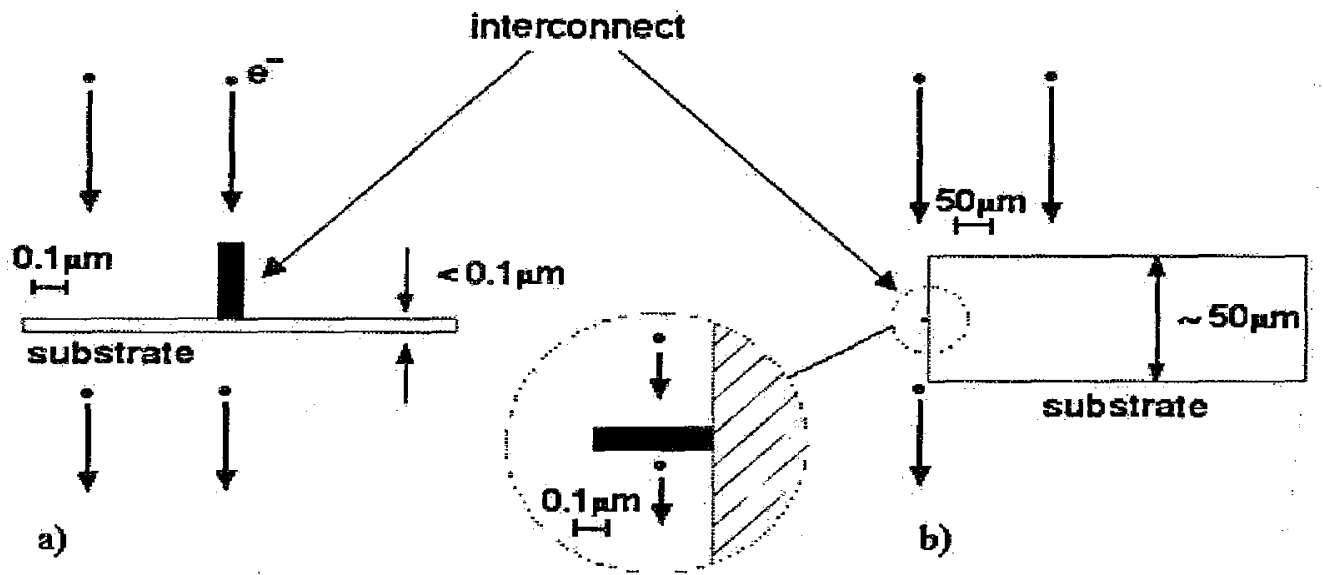

Figure 2. Substrate and beam configuration for a) plan and b) Side-view observation in STEM. 
In STEM, one normally looks at a thin interconnect which is laid on a thin substrate for plan view observation, but we propose to use the side view approach (Figure 2) to look at the interconnect alone on a thick substrate - so as to preserve both the normal thermo-mechanical conditions and the normal STEM spatial resolution.

For the validation of our in situ approach, we have fabricated nanoscale wires that are suitable for in situ electromigration observation in STEM and we have observed the annealing of sputter deposited aluminum films with metal and substrate thicknesses that are comparable with the metal and dielectric of future interconnects.

\section{Experiment}

\section{Fabrication of nanoscale interconnects}

Depositions were conducted in a VG Microscopes model HB5 scanning transmission electron microscope (STEM) which was modified by the addition of a gas introduction system. Molecules liberated from an organometallic liquid in a stainless steel storage vial were supplied through a custom gas dosing nozzle adjacent to the substrate surface.

The STEM was operated to provide $100 \mathrm{keV}$ primary electrons in a probe of diameter less than $10 \mathrm{~nm}$ diameter and with a probe current about $0.15 \mathrm{nA}$. The pattern scanned by the probe was controlled by an analog scan generator. Sets of four lines were repeatedly scanned at constant probe velocity with a line time of $5 \mathrm{~ms}$, and single lines were scanned at a line time of 20 $\mathrm{ms}$, for a total of 3 minutes. Electrically controlled beam blanking enabled the deposition only at chosen locations and for known durations and also enabled monitoring of the electron beam current at any time without additional electron exposure of the substrate.

The base pressure near the substrate was less than $1 \times 10^{-8}$ Torr and the partial pressure of organometallic vapor admitted near the substrate was estimated to be about $1 \times 10^{-6}$ Torr. We have used dimethylethylamine alane (DMEAA) as the orgonametallic precursor for electron induced deposition. The substrates for this work were self-supporting $10 \mathrm{~nm}$ thick carbon and 50 nm thick polycrystalline silicon films (ACF Metals, 2239 East Kleindale Rd. Tucson, AZ) and were maintained at a temperature of $-82^{\circ} \mathrm{C}$.

\section{Fabrication and in-situ observation of aluminum films}

The substrates for sputtered Al films were silicon nitride membrane windows of $25 \mathrm{~nm}$ thickness on $200 \mu \mathrm{m}$ silicon supports (SPI Supplies, PO Box 656, West Chester, PA). Aluminum films $130 \mathrm{~nm}$ thick were deposited a rate of $0.5 \AA / \mathrm{sec}$ onto these substrates from a $2.5^{\prime \prime}$ aluminum target of $99.999 \%$ purity by room temperature dc magnetron sputtering in $1.7 \times 10^{-3}$ Torr pressure of ultra high purity grade argon. The initial base pressure and the deposition power were $4 \times 10^{-7}$ Torr and $300 \mathrm{~W}$ respectively.

The films were then annealed in a VG HB501 scanning transmission electron microscope (STEM) in vacuum $\sim 4 \times 10^{-8}$ Torr for 2.5 hours at a temperature of $350{ }^{\circ} \mathrm{C}$. During annealing, annular dark field (ADF) images of the morphological changes of the deposited film were recorded using both a VCR and computer image capture. 


\section{Results and Discussion}

Initial electron beam-written deposits at $-82{ }^{\circ} \mathrm{C}$ on both $\mathrm{Si}$ and $\mathrm{C}$ substrates using DMEAA molecules are quite similar in shape and appearance, despite the differences in the surface nature and electrical conductivity of the substrates. This is consistent with a lack of sensitivity to the exact nature of the substrate. Following the deposition, aluminum containing deposits from DMEAA on carbon and silicon were examined in transmission in the STEM using annular dark field (ADF) imaging, which is highly sensitive to the projected density-thickness product of material in the viewing direction. The resulting deposits are shown in Figure 3.

These deposits are essentially uniform, continuous and confined to the locations of the electron beari, as might be expected for a radiation-induced, surface mediated deposition process in which local heating of the substrate plays no part. If heating were an important factor, deposition would be expected adjacent to the electron irradiation portion of the substrate; any significant heating would limit the smallest width and the edge acuity of the deposited structures.

a)

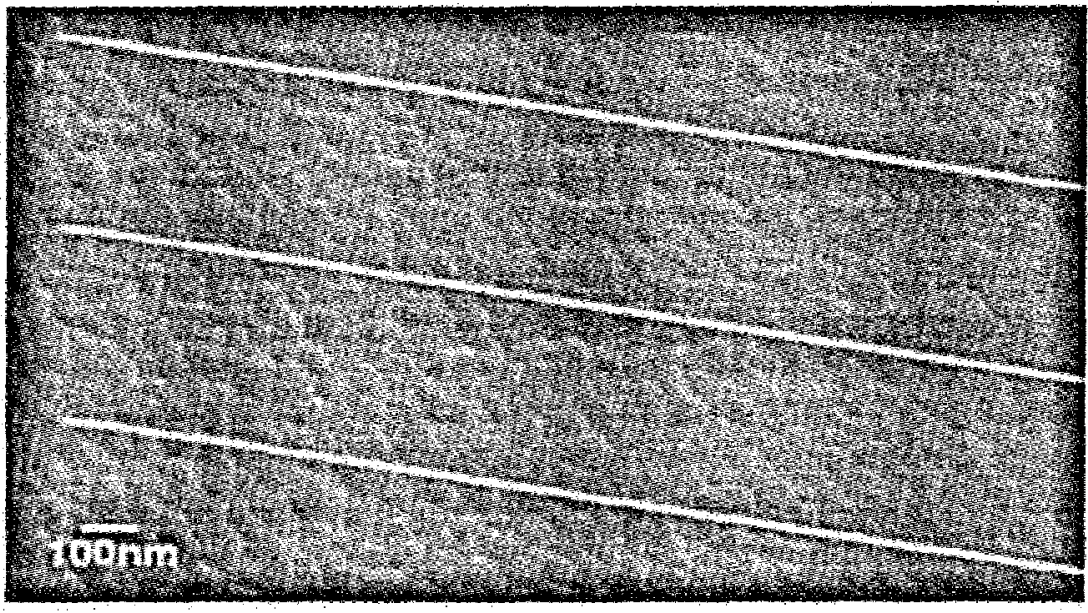

b)

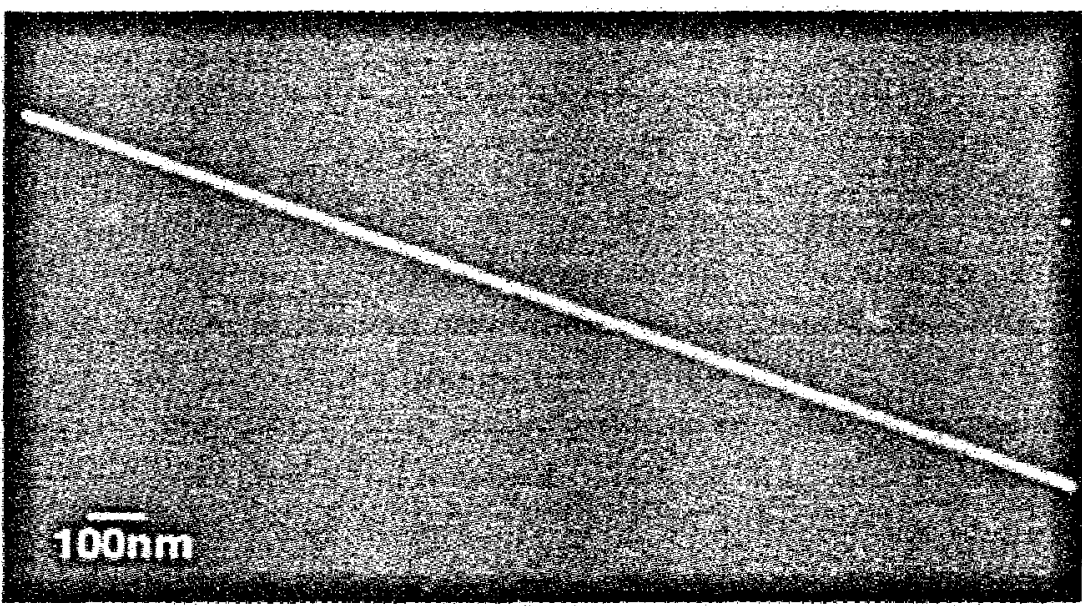

Figure 3. Annular dark field (ADF) images of electron beam-induced line deposits from dimethylethylamine alane a) on $50 \mathrm{~nm}$ thick polycrystalline silicon substrate and b) on a $10 \mathrm{~nm}$ thick carbon substrate. 
Once process optimization is completed, it is expected that the best feature resolution will be much less than $15 \mathrm{~nm}$. It will then be possible to trade feature resolution for process time according to the demands for each patterned structure.

Other organometallic precursors and substrates are under investigation. For our investigation of nanoscale interconnects, thin dielectric layers will be deposited on the aluminum wires to generate model systems that have somewhat more realistic stress states, by virtue of the mechanical constraints provided by the dielectric. The goal, of course, after validation of the in sifu approach, is to study passivated deep submicron interconnects that are prepared by standard microelectronic fabrication procedures.

Several annular dark field (ADF) STEM images, recorded at intervals during the annealing of a sputter deposited aluminum film, are presented in Figure 4. The contrast of these images has been increased for display. In addition to intensity variations associated with the film thickness at each pixel, the images also contain slight diffraction contrast variations. This contrast is apparent from the banding in one grain (arrowed) and from the relatively strong intensity changes from grain to grain. From TEM observations of the Al film before and after annealing, we measure an increase in average grain size from $\sim 51 \mathrm{~nm}$ to $\sim 60 \mathrm{~nm}$, that is consistent with the slight grain changes visible in the ADF images of Figure 4. Elsewhere, a few areas of the film relaxed by hole formation. These thin film observations are consistent with those of Smith et al (1991) for somewhat thicker films [12].

The diffraction contrast in Figure 4 accounts for, at most, $20 \%$ of the total variation in the ADF signal but will be suppressed almost completely by changing to high angle (HAADF) imaging. The $A D F$ image resolution, even at $350^{\circ} \mathrm{C}$, is better than $10 \mathrm{~nm}$ and this is likely to be unchanged on replacement of the present $\mathrm{ADF}$ detector by a high angle detector.
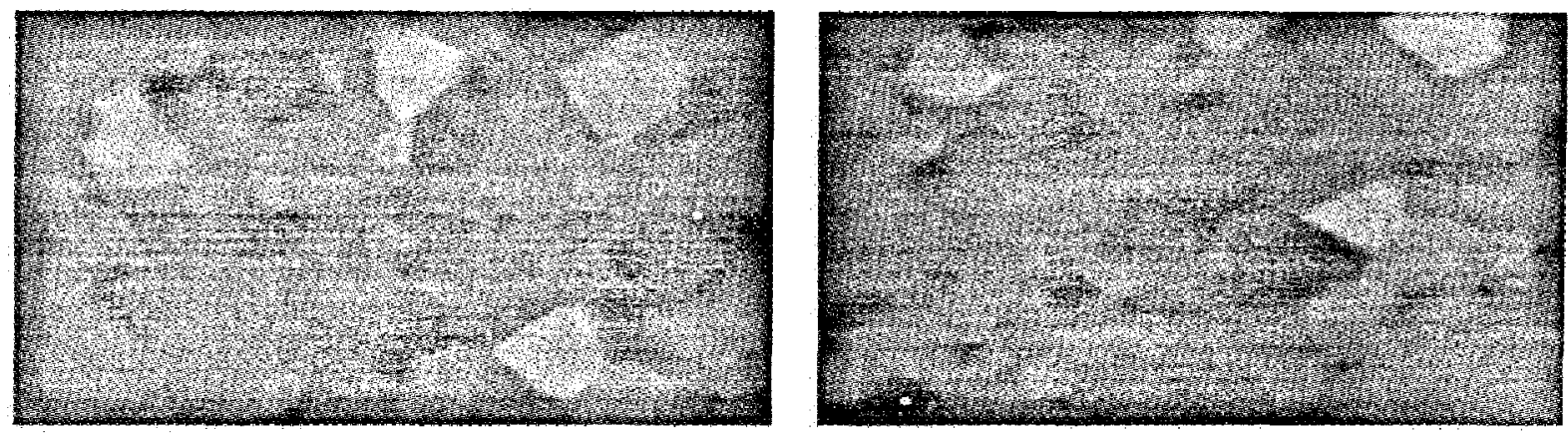

$\mathrm{t}=0 \mathrm{~min}, \mathrm{~T}=23^{\circ} \mathrm{C}$
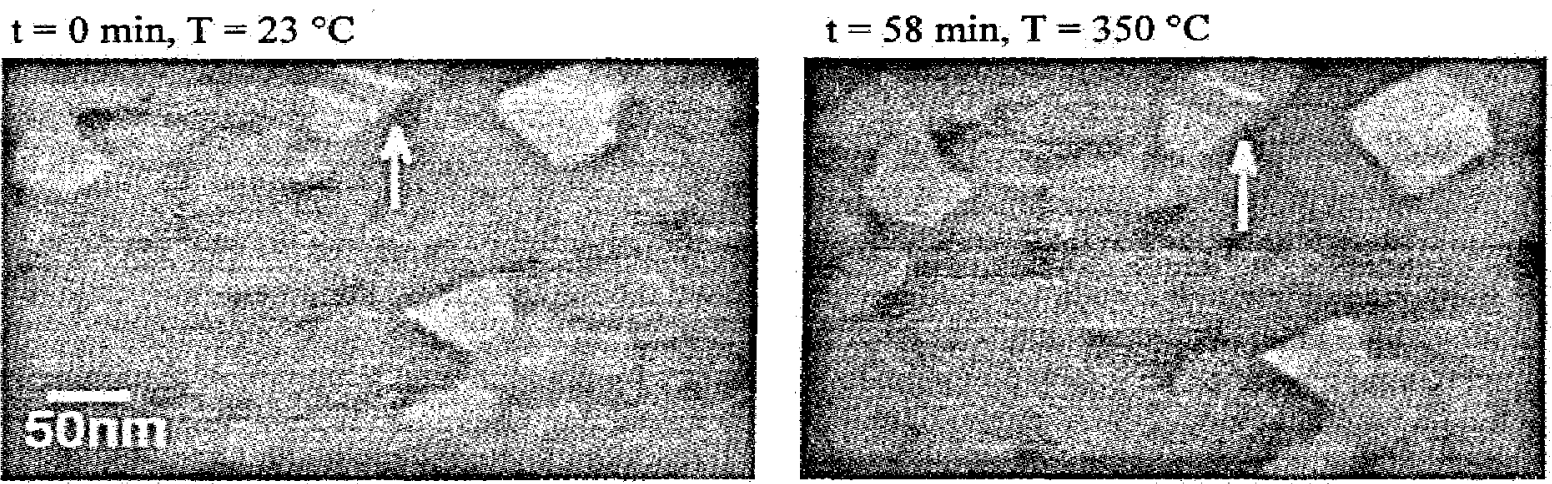

$$
\mathrm{t}=68 \mathrm{~min}, \mathrm{~T}=350^{\circ} \mathrm{C}
$$

$$
\mathrm{t}=84 \mathrm{~min}, \mathrm{~T}=350^{\circ} \mathrm{C}
$$

Figure 4. In situ ADF real time images acquired during annealing. 


\section{Conclusions}

We have proposed an approach for simultaneous, real time in situ dynamic observation of structural, compositional and morphological changes during electromigration testing. In test conditions that are substantially equivalent, we have shown that field emission STEM provides the resolution that is required for complete characterization of nanoscale interconnects in situ during electromigration testing. We have substantially validated the in situ STEM approach by obtaining images with better than $10 \mathrm{~nm}$ resolution during annealing of thin $\mathrm{Al}$ on a $\mathrm{Si}_{3} \mathrm{~N}_{4}$ substrate. We have also successfully deposited aluminum containing wires with $15 \mathrm{~nm}$ line widths, sharp edges, and uniform thicknesses, thus confirming the potential for in sifu fabrication of model nanoscale interconnect test structures.

\section{Acknowledgements}

The authors gratefully acknowledge support from the Office of Naval Research, the Air Force Office of Scientific Research and the National Science Foundation. The authors also thank Natalie J. Ianno and Hesham Enshasy (Electrical Engineering, University of Nebraska-Lincoln) for provision of the sputtered aluminum films and Bethlehem Steel for the loan of a cold stage for the VG STEM.

\section{References}

1. S. Lee, J. Doan, J. C. Bravman, P. A. Flinn, T. N. Marieb, S Ogawa in AIP Conference Proceedings No. 418 (Stress Induced Phenomena in Metallization. Fourth International Workshop, 1998), pp. 101-106.

2. R. Frankovic and G. H. Bernstein, (Mater. Res. Soc. Proc. 404, 1996), pp. 163-169.

3. K. L. Lee, C. K. Hu and K. N. Tu, J. Appl. Phys. 78 (7), 4428-4437 (1995).

4. W. C. Shih and A. L. Greer, Thin Solid Films 292, 103-117 (1997).

5. H. Okabayashi, M. Komatsu and H Mori, Jpn. J. Appl. Phys. 35, 1102-1106 (1996).

6. H. Schroeder and D. Heinen in Stress Induced Phenomena in Metallization: Fourth International Workshop, edited by Okayabashi, Shingubara and Ho (Amer. Inst. Phys. Proc. 418, 1998) pp. 183-194.

7. S. P. Riege, J. A. Prybyla and A. W. Hunt, Appl. Phys. Lett. 69 (16), 2367-2369 (1996).

8. M. Paniccia and R. Reifenberger, Amer. Inst. Phys. 1994, pp. 211-219.

9. M. Kumikawa and H. Komoda, Jpn. J. Appl. Phys. 31, LL1147-LL1 149 (1992).

10. K. Masu, Y. Hiura, K. Tsubouchi, T. Ohmi and N Mikoshiba, in Extended Abstracts of the 1991 International Conference on Solid State Devices and Materials, Yokohama, 1991, pp. 126-128.

11. B, R. York, H. L. Pfizenmayer, C. H. Lee and R. O. Carnes, (Mater. Res. Soc. Proc. 428, 1996), pp. 557-563.

12. U. Smith, N. Kristensen, F. Ericson and J-A. Schweitz, J. Vac. Sci. Technol. A 9 (4), $2527-$ 2535 (1991). 